\title{
Microorganisms from harsh and extreme environments: a collection of living strains at ACUF (Naples, Italy)
}

\author{
Luigi D’Elia' ${ }^{1,2}$, Angelo Del Mondo ${ }^{1 *}$, Mariano Santoro ${ }^{1,3}$, Antonino De Natale ${ }^{1}$, \\ Gabriele Pinto ${ }^{1}$, Antonino Pollio ${ }^{1}$
}
${ }^{1}$ Department of Biology, University of Naples "Federico II", Via Cinthia 26, 80126 Naples, Italy e-mail: angelo.delmondo@unina.it
${ }^{2}$ Department of Chemistry, University of Naples "Federico II", Via Cinthia 26, 80126 Naples, Italy
${ }^{3}$ InBioS-Centre for Protein Engineering, University of Liège, Sart Tilman, 4000 Liège, Belgium

Received: 28 April 2018 / Accepted: 22 July 2018

\begin{abstract}
The Algal Collection at the University Federico II (ACUF) is a bioresource center where over 800 live microalgal strains are maintained, mainly belonging to Cyanobacteria, Chlorophyta, Rhodophyta, and Bacillariophyceae. The extremophilic algae maintained at ACUF include thermo-acidophilic and acidotolerant strains, mostly belonging to the Cyanidiophyceae isolated from European and extra-European sites, and also terrestrial isolates from bare rocks and monuments. The main target of the ACUF Center is the study and preservation of the diversity of extremophylic microalgae. This collection is used as a resource for studies about biochemical and evolutionary strategies as well as mechanisms involved in cell functioning under harsh environmental conditions. These organisms can be also useful sources for the production of chemical compounds or other biological products with potential biotechnological applications.
\end{abstract}

Keywords: Culture collection, extreme environments, microalgae, biodiversity, biotechnology

\section{The ACUF collection}

Extreme environments are typically characterized by harsh conditions determined by spatial gradients of chemical and physical factors, consisting of strong variations in temperatures, humidity, salinity, and $\mathrm{pH}$. They are usually represented by hot and cold deserts, hot springs, salt lakes, volcanic and thermal areas, sulfide mines near deep-sea vents as well as terrestrial environments exposed to desiccation and sharp variations of temperature, as bare rocks, but also building facades and monuments. Extremophilic microorganisms are exposed to hostile conditions and are categorized on the basis of their ability to thrive in a specific type of niche (Rampelotto, 2013). During the past 45 years ACUF collection based at the Federico II University of Naples (Italy) has supported the study of photoautotrophic microorganisms dwelling those habitats. The aim of this article is to present the most significant features of ACUF collection, examples of applied research carried out by the ACUF staff, strains of interest and future directions in the preservation and study of biodiversity. Table 1 provides a complete list of the strains maintained in the ACUF collection classified according to Division, Class, and Order.

\section{History and aims}

The culture collection of algae at the Federico II University of Naples was started in 1973 by professor Roberto Taddei, and was initially planned as a collection of Cyanidium caldarium Geitler (sensu lato) strains from different acidic-thermal sites of Italy (De Luca et al., 1973) and other countries (De Luca et al., 1977). Further investigations on acidic and thermal sites of Italy (Fig. 1a and b) led to the 
Table 1. Taxonomical distribution of the strains presently maintained in the ACUF Collection

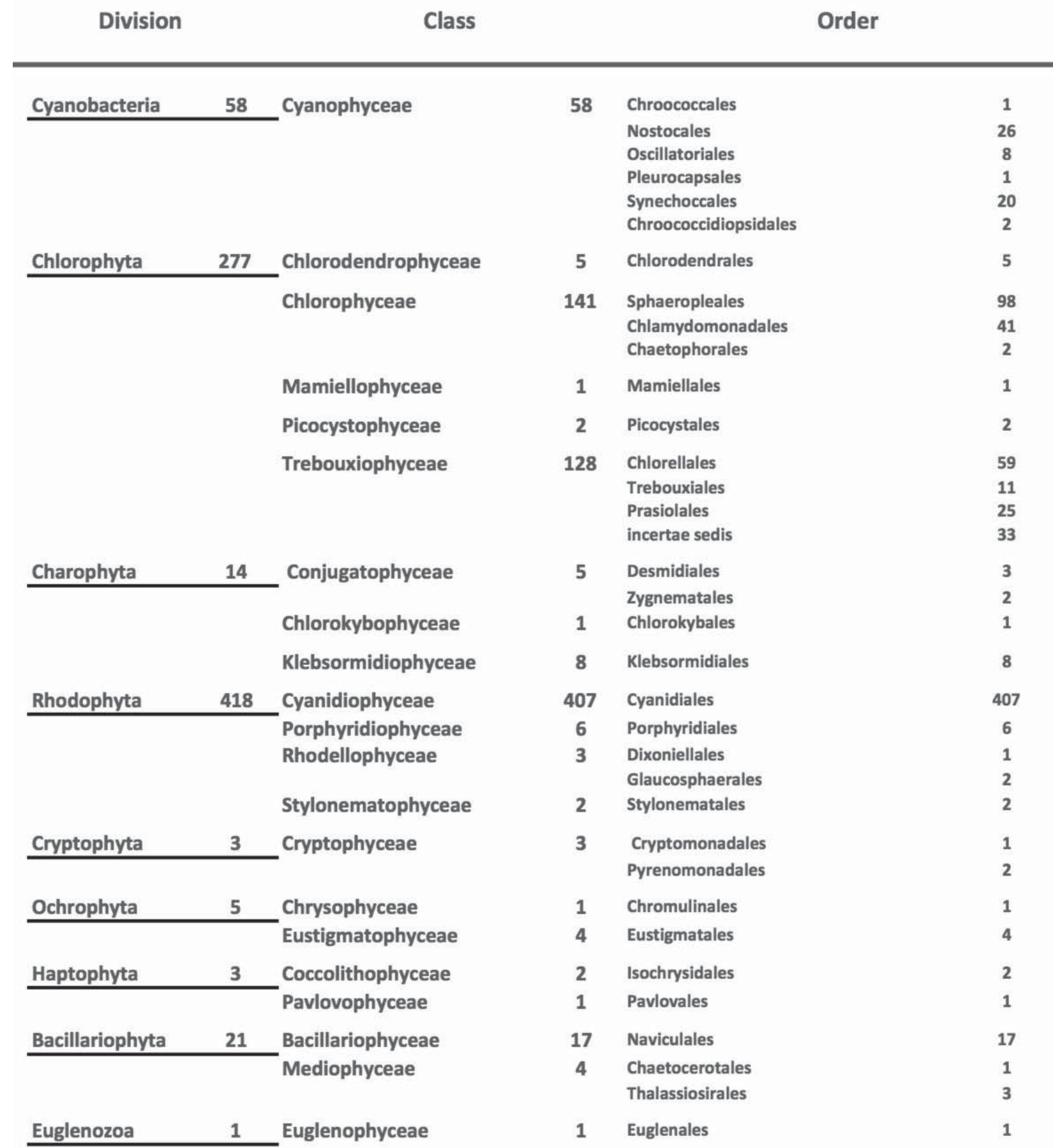

Total strains

800

isolation of acido-resistant species belonging to Chlorophyta, Bacillariophyta and other divisions (Pinto and Taddei, 1977). In the late 1970's the C. caldarium collection was expanded to similar sites of different countries, with a focus on Central and North America.
In these explorations, strains from Yellowstone National Park, Playon de Auachapan (El Salvador), Los Azufres and Cerro Prieto (Mexico) were collected (Gambardella et al., 1980). Following the American explorations, an expedition to Mount Lawu in Java (Indonesia) allowed to col- 
lect Cyanidiophyceae in the type locality of $C$. caldarium (De Luca et al., 1981). Afterwards, in 2006 and at a later stage in 2011, Pinto and Ciniglia increased considerably the number of Cyanidiophycean strains in the ACUF collection with the explorations of thermal and acidic sites in Iceland (Fig. 1c) (Ciniglia et al., 2014) and Turkey.

\section{Microalgae from thermoacidic habitats}

During the years, ecophysiological and ultrastructural studies were conducted on chlorophycean microalgae isolated from low $\mathrm{pH}$ environments, as Chlamydomonas pitschmannii Ettl (Pollio et al., 2005), Stichococcus bacillaris Nägeli (Pollio et al., 1997), Pseudococcomyxa simplex (Mainx) Fott (Albertano et al., 1990) and Auxenochlorella protothecoides (Krüger) Kalina et Puncochárová (Albertano and Taddei, 1984) together with the newly described species Viridiella fridericiana Albertano, Pollio, Taddei (Albertano et al., 1991). Also the chrysophyceaen Ochromonas vulcania Gromov (Albertano et al., 1994) and the bacillariophycean Pinnularia obscura Krasske (Ciniglia et al., 2007) thriving in acidic ponds of Southern Italy were collected and studied.

A major focus was dedicated to Cyanidiophyceae. Unicellular terrestrial Rhodophyta have been considered as a single species for a long time, and described for the first time as Coccochloris orsiniana by Meneghini (1839). Almost a century later, this species had been placed in a number of already described genera, falling either to the Cyanophyta or Chlorophyta, until Geitler assigned to this species the generally accepted binomial Cyanidium caldarium. The taxon was officially recognized as part of the Rhodophyta by Hirose (1958), who demonstrated the presence of several characteristic rhodophycean features. Later, De Luca et al. (1978) described the new species Cyanidioschyzon merolae De Luca, Taddei, Varano, featured by its characteristic size and shape, whereas Merola et al. (1981) differentiated Galdieria sulphuraria (Galdieri) Merola from $C$. caldarium based on its ability to grow in the dark. Currently, macroevolutionary studies integrate aspects of biogeography and geography in a phylogenetic context to answer questions related to the world diffusion of Cyanidium, Galdieria, and Cyanidioschyzon. Molecular phylogenetic studies suggest that the Cyanidiales represent one of the most ancient groups of algae, having diverged about 1.3 billion years ago at the base of the Rhodophyta (Müller et al., 2001; Yoon et al., 2002b).

\section{Algal biofilms and cultural heritage}

Although most green algae typically thrive in aquatic environments, many species also live partly or permanently under aero-terrestrial conditions; microorganisms living at rock-atmosphere interface experience dehydration regularly, a phenomenon described as desiccation tolerance (Holzinger and Karsten, 2013). Microbial biofilm development can be observed on virtually all kinds of stone monuments such as castles, caves, churches/cathedrals, fountains, temples, tombs/catacombs, etc. (Fig. 1d, e and f), and can be associated with problems of conservation. Several types of autotrophic and heterotrophic microorganisms such as bacteria, fungi, algae and lichens, are usually observed on stone monuments. The rock substratum provides harsh environmental conditions. Temperature may vary by several tens of degrees during a day, and can be accompanied by rapid desiccation (or freezing); all that implies a limited availability of water (e.g., Walker and Pace, 2007). The ACUF team characterized and studied biofilm communities on stone monuments in the archaeological sites of Campania (Italy), namely Pompeii, Herculanuem, Oplontis, Cumae and Nola among others. Microorganisms retrieved on monuments were analysed in their native biofilm structure by CLS-microscopy, isolated, characterized, and subsequently used as models to perform in vitro experiments for understanding the patterns of microbial colonization of stone materials (Marasco et al., 2016; Del Mondo et al., 2017).

\section{Biotechnological applications and toxicity tests}

Microalgae can be employed in a wide number of biochemical and biotechnological applications. In recent years, wastewater treatment, biodiesel production, biopolymers and nutraceutical science have become hot topics. In response to the uprising energy crisis, climate change and depletion of natural sources, advantages in the use of microalgae for biotechnological applications are represented by their capability to grow on non-arable lands nearly all year long, thus non competing with conventional agriculture. As a matter of fact, they only require freshwater, non-organic nutrients, and atmospheric $\mathrm{CO}_{2}$. Moreover, their cultivation may be coupled to industrial processing, i.e. reducing overall carbon dioxide emission or for wastewater treatment. Given this premise, collections of extremophilic microorganisms allow the selection of strains that produce high value compounds with specific features as thermo-resistance or cryo-resistance; this may also prevent environmental microbial contaminants that would not survive the selected growth conditions (Ruiz et al., 2016).

Biofuels production by microalgae appeared promising since the end of the last century: bio-oil extracted from microalgae may be adopted as crude fuels or may be transesterified to biodiesel. In a study conducted by Olivieri et al. (2010) the strain ACUF 158 S. bacillaris has been selected as a promising candidate for biofuel production; in fact, this strain is characterized by satisfactory lipid content $(33 \%)$ and fatty acids distribution; moreover, the high tolerance of this strain to large variations of temperature, salinity and $\mathrm{pH}$ allows massive cultures to be operated un- 
der severe conditions, thus preventing bacterial and fungal contamination.

Risk characterization is an estimation of the incidence of the adverse effect occurring in an environmental compartment as a result of actual or predicted exposure to a substance. In a study by Ferrari et al. (2003), the occurrence in sewage treatment plant (STP) effluents and ecotoxicity of the pharmaceuticals carbamazepine, clofibric acid, and diclofenac has been investigated testing growth inhibition of the microalga Raphidocelis subcapitata (Korshikov) Nygaard, Komárek, Kristiansen et Skulberg (Pseudokirchneriella subcapitata (Korshikov) Hindák). This species is a standard test microalga recommended by U.S. EPA (Environmental Protection Agency, 1989) and OECD guidelines (Organization for Economic Co-operation and Development, 1993). In another study, Ciniglia and co-workers (Ciniglia et al., 2005) examined the toxic effects of Triclosan (2,4,4'-trichloro-2'-hydroxydienyl ether) on the morphology and sexual and asexual reproduction of Closterium ehrenbergii Meneghini ex Ralfs, proposing the species as an ideal target for assessing the toxicity of pharmaceutical products and personal care products (PPCP).

Finally, it is internationally agreed that water and sanitation are essential to the achievement of many sustainable development goals (WWDR, 2015); the application of microalgae for wastewater treatment represents a suitable technological solution. One of the contributions of ACUF in this area was represented by the treatment of olive oil mill wastewaters with the phenol resistant algae Ankistrodesmus braunii (Grunov) Cleve and Scenedesmus quadricauda (Turpin) Bréb, which are able to degrade over $50 \%$ of low molecular weight phenols contained in oil mill wastewaters and bio-transform them into other non-identified aromatic compounds (Pinto et al., 2003).

\section{Facilities and culture maintenance}

The phycological lab at ACUF has established growth rooms and growth cabinets for cultures of cyanobacteria and microalgae at different biomass scales and under dif-
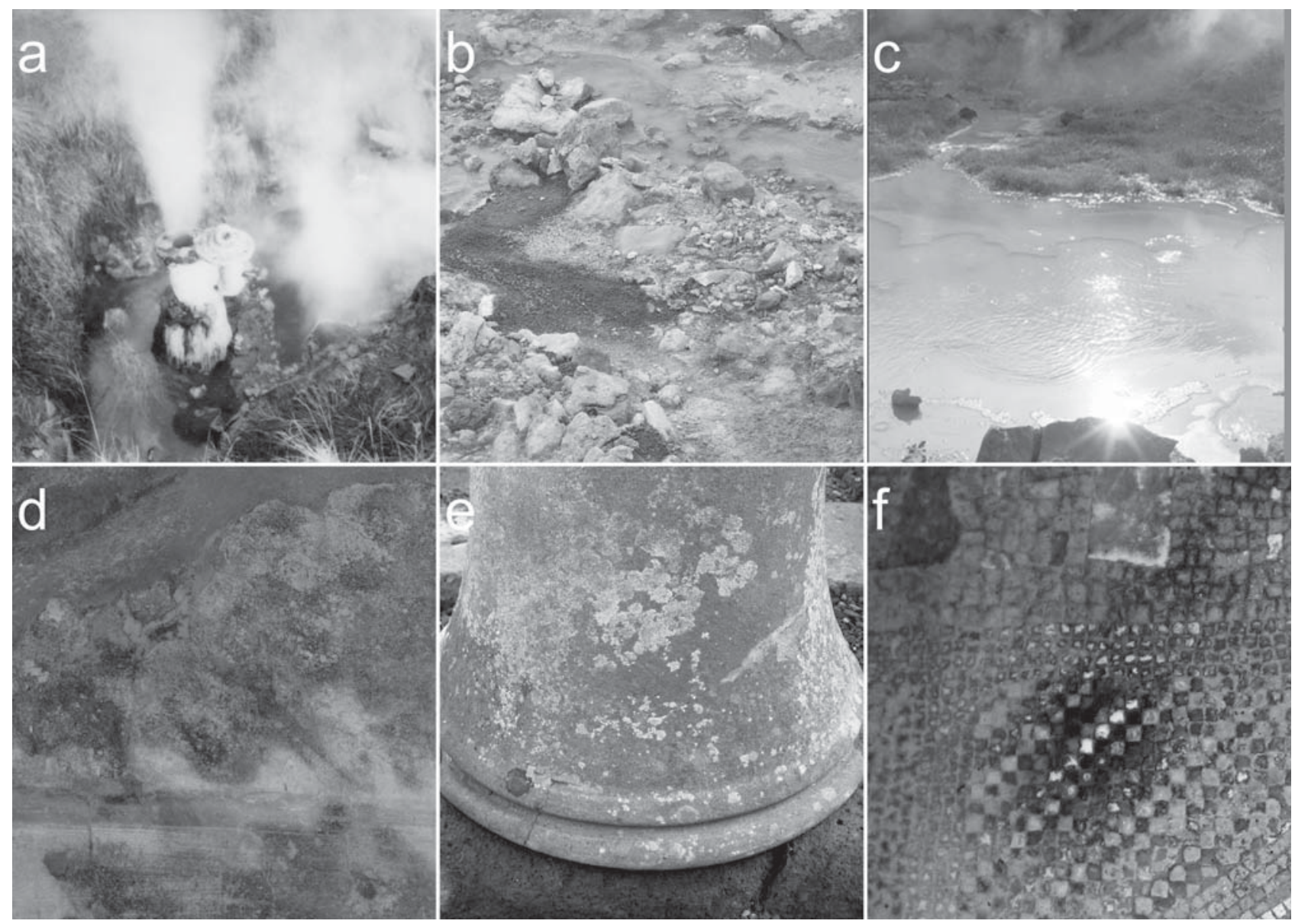

Fig. 1. Algal sampling sites: a) Ali Terme, Spa Granata Cassabile, Messina; b) Pisciarelli, Napoli; c) Hveragerdi, Iceland. Example of Pompeian biofilms on: d) fresco; e) stone column; f) polychrome mosaic 
ferent environmental conditions. Most of ACUF strains are maintained in glass tubes at a range temperatures between $22^{\circ} \mathrm{C}$ and $26^{\circ} \mathrm{C}$ with various solid culture media as BG11, BBM and Allen (using Agar as solidifying agent). Few strains (mostly belonging to Bacillariophyceae) are maintained in liquid cultures at a temperature of $18^{\circ} \mathrm{C}$. Cultures grow at an irradiance of $150 \mu \mathrm{mol}$ photon $\mathrm{m}^{-2} \mathrm{~s}^{-1}$ with a 16:8 h light-dark cycle. Under these conditions, transfers are made routinely every 1-2 months, although for many species four or six months intervals would be sufficient. An overview of some facilities employed for biomass recovery is displayed in Fig. 2. Different types of photobioreactors and fermenter are used to produce significant amounts of algal biomass for biotechnological applications. The cylindrical photobioreactors are $1 \mathrm{~L}$ bubble columns made of glass (0.04 m ID, $0.8 \mathrm{~m}$ high, see Fig. 2b); air is sprayed at the photobioreactor bottom by means of a porous ceramic diffuser. Flat photobioreactor systems are made of plexiglass panels (Fig. 2d) spaced by two, $3 \mathrm{~mm}$-thick, silicone sheets conveniently cut out to outline the reactor and separate the plexiglass sheets. Panels absorb only $1 \%$ of the incident irradiance (measured by light sensor Li-cor). The final volume of the culture is $0.3 \mathrm{~L}$. Gas stream is spread into the culture from the bottom of the photobioreactors through four $1 \mathrm{~mm}$ orifices (Gifuni et al. 2017, 2018).

All photobioreactors are housed in a temperature controlled chamber equipped with lamps at a light irradiance (IL) set at $140 \mu \mathrm{mol}$ photon $\mathrm{m}^{-2} \mathrm{~s}^{-1}$. Measurements of photosynthesis and respiration rates (OUR) are carried out on culture sub-samples at the irradiance adopted in climate chambers by means of an Oxygraph (Hansatech) connected to a $\mathrm{PC}$.

\section{Strain isolation procedures}

Isolates constitute the main resource for ACUF: the primary focus is to maintain an assessment of algal diversity in unusual terrestrial habitats for mainly three reasons: i) to better understand phylogenetic relationships of the still poorly investigated terrestrial algae and to recover new species; ii) to test and develop new methods for assessing algal diversity in a given habitat; iii) to isolate algal communities from biofilms and in soils to better understand the
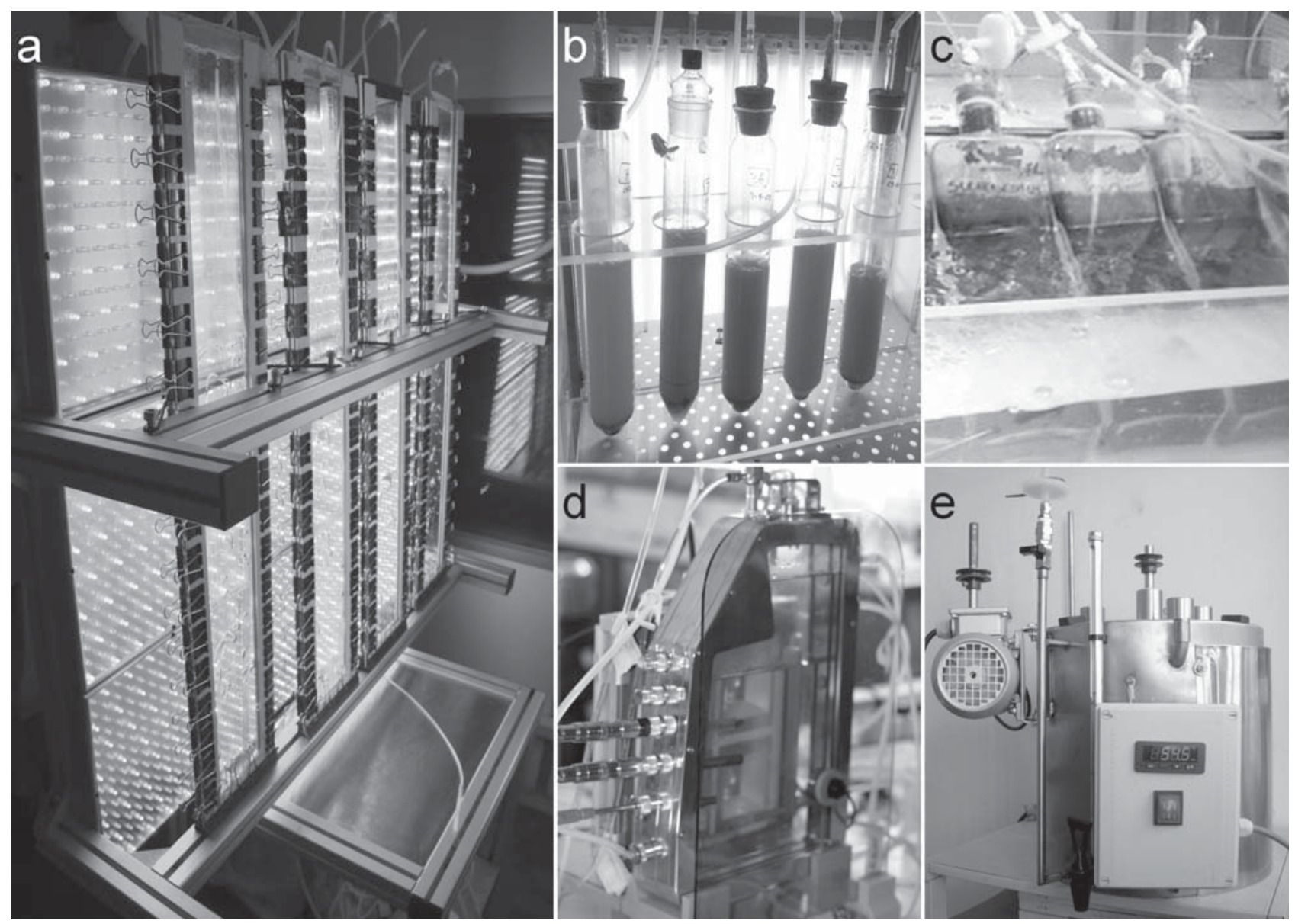

Fig. 2. Different kind of bioreactors a-d, a) ultra-flat; b) bubble column; c) inclined square bubble column; d) flat; e) a fermenter 
ecological preferences of terrestrial algae and their interactions with substrates and/or other microorganisms.

Strains in ACUF Collection come from samples collected by members of the host lab and by external depositors. It is a constantly growing Collection of new unique isolates, mainly regarding aero-terrestrial and aquatic habitats. New isolates are subjected to a preliminary screening for morphological traits, growth characteristics, and their phylogenetic relatedness to already known species.

Different culture media have been tested: BBM (Bold, 1949; Bischoff, 1963), BG11 (Rippka et al., 1979) and Allen medium (Allen, 1959) support a consistent growth of the large majority of the strains. For species belonging to the Cyanidiophiceae that usually live in habitat with a $\mathrm{pH}$ of $1.0-3.5$, we use Allen medium acidified by $\mathrm{H}_{2} \mathrm{SO}_{4} 7 \%$. Isolation of filamentous microalgae is done at a binocular microscope and the standard techniques of sterile handling in horizontal laminar flow cabinets (HF 72, Gelaire Flow Laboratories) are applied (Rippka et al., 1981).

\section{Characterization and monitoring of cultures}

\section{Aim of a polyphasic approach}

Until recent times, identification of prokaryotic and eukaryotic microorganisms has been based on morphological features and in a few cases ecological features; the intro- duction of molecular techniques used for diversity studies has given a significant contribution to integrate the species identification knowledge in the taxonomical context. The integrated approach used at ACUF relies on the morphological and molecular characterization in order to investigate the diversity of microorganisms from extreme ecological habitats. Furthermore, phylogenetic analyses are carried out in order to study biogeography and distribution of different ecotypes of species, with a particular attention to Cyanidiophiceae. This kind of approach is also defined "polyphasic" and it is currently used for strain isolation and identification at ACUF as detailed in the workflow in Fig. 3.

\section{Optical, epifluorescence and CLS Microscopy}

Strain identification at species level foresees that microphotographs are taken by the light microscope Nikon Eclipse E800 for all strains. At ACUF, also epifluorescence microscopy is used to observe photosynthetic pigment composition and specific cell staining are carried out by using specific dyes as DAPI or concanavalin-A to stain nuclei and extracellular EPS, respectively. Moreover, CLSMicroscopy enables us to study environmental samples on lithic substrates as well as biological structures of interest also in $3 \mathrm{D}$, like plastidial organization (Izabela et al., 2008). Image analysis of Z-stacks allows to analyse specific patterns in meta-community, biological associations

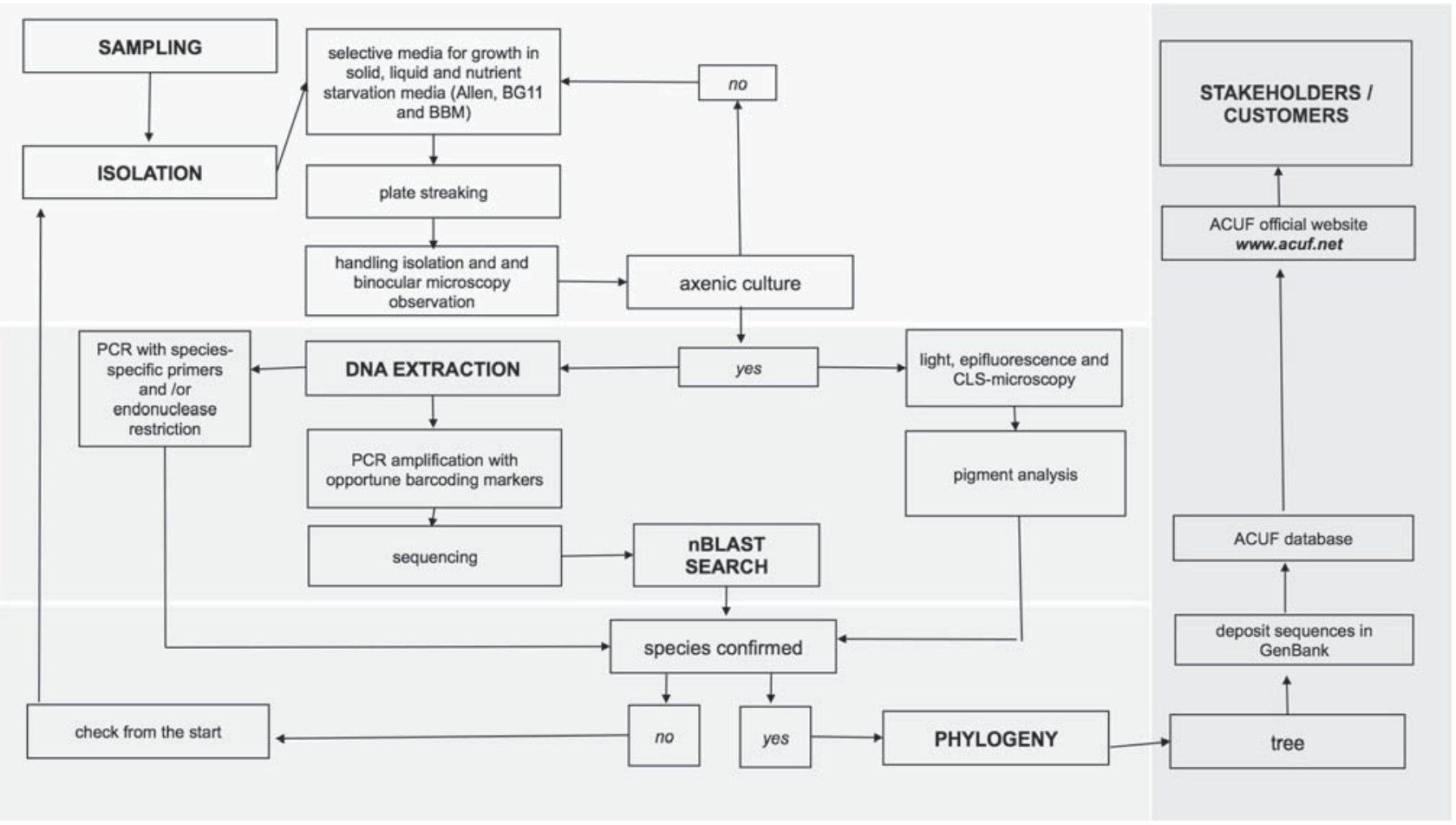

Fig. 3. Workflow of ACUF polyphasic approach for strain isolation and identification 
and to monitor interaction of microorganisms with their living substrate.

\section{Pigment analysis}

Photosynthetic pigments are revealed at ACUF through spectrophotometric analysis to build a library reference: the procedure consists on determination of chlorophyll a, chlorophyll b, carotenoids and many others, following accurate methods well known in literature (Wellburn, 1994). This allows a first screening of isolated cultures, and the annotation of peculiar pigment composition in microalgae (Aminot and Rey, 2000).

Also hand-fluorometry is used when the available volume of water is not enough for reliable absorbance measurement; however, fluorometers need to be calibrated with chlorophyll standards for a preliminary calibration curve. In some cases, Reversed-Phase High Performance Liquid Chromatography (HPLC) is also used to characterize the quantity of Chlorophyll a and accessories pigments of strains preserved at ACUF Collection.

\section{Molecular analysis and genetic barcoding markers}

Cellular lysis for DNA extraction is performed selectively with the aid of bead beater, chemical lysis and freeze-andthaw, or a combination of these methods. DNA extraction is carried out following the protocol by Doyle and Doyle (1990). Purified DNA is then quantified with NanodropD-1000 (Thermo Fisher Scientific - Wilmington, Delaware USA) and subsequently run on agarose gel electrophoresis for quality evaluation. Amplification by Polymerase Chain Reaction is carried out with primer sets specific for the different algal groups. Purified PCR products are then sequenced by Sanger method and the obtained sequences are compared by BLAST search and used for inferring phylogeny and species-attribution.

A number of molecular markers are used at ACUF for the identification and phylogenetic analyses: (i) ITS1 and ITS2 (internal transcribed spacers) (Wang et al., 2015) are used for barcoding green microalgae; ITS1 has been preferred to investigate phylogenetic relationships in several lineages of green algae (Hall et al., 2010; Cozzolino et al., 1999) whilst the secondary structure of ITS2 has been proposed particularly for the characterization of closely related species among Chlorophyta (Caisová et al., 2013; Fucíková et al., 2013); (ii) the $16 \mathrm{~S}$ rRNA gene is a broadly used molecular marker for Cyanobacteria and, more generally, for prokaryotes; (iii) the rbcL (plastid Rubisco large subunit) gene is a marker that can resolve the attribution of several microalgal species, especially when used in combination with nuclear barcoding markers (Zou et al., 2016). At ACUF, species-specific primers have been designed for the discrimination of Cyanidiophyceae.
Specific cases of phylogenetic attribution can be resolved with the help of a number of other markers. Among these, plastidial gene tufA (elongation factor (EF)-Tu) (Fama et al., 2002; Vieira et al., 2016) for green algae, and nifH (nitrogenase reductase) (Zehr et al., 1997) and cpcA (phycocyanin alfa subunit) (Manen and Falquet, 2002) for Cyanobacteria have been proposed. Extending the information deposited in public sequence database - in terms of number of different molecular markers and number of sequences - is fundamental in order to accurately determine the conclusive phylogenetic attribution for known species as well as for novel species described.

\section{Overview of the available strains and representativeness of cultures}

Presently, over 800 strains of eukaryotic microalgae and cyanobacteria are cultivated in the ACUF collection. The vast majority of microorganisms held at ACUF collection is composed by Archaeplastida that groups all eukaryotes with plastids derived from primary endosymbiosis: in fact, $89 \%$ of the ACUF strains belongs to the Divisions Chlorophyta, Rhodophyta, and Charophyta. About $7 \%$ of the entire collection is represented by photosynthetic prokaryotes belonging to different Orders.

The most representative taxonomic groups are Rhodophyta (418), Chlorophyta (277), and Cyanobacteria (58). In particular, among Rhodophyta the vast majority is represented by Cyanidiophyceae, while among Chlorophyta, the classes of Trebouxiophyceae and Chlorophyceae account for the widest species diversity. Collection also includes strains sampled in saline ore thermo-acidic environments belonging to the divisions of Charophyta (14), Ochrophyta (5), Cryptophyta (3), Haptophyta (3), and Euglenozoa (1) (for further details see Table 1).

The cultured strains were mainly isolated from terrestrial habitats, especially in proximity of hot springs, geysers and sulphuric fumaroles, but also on bare lithic substrates, or monuments (Fig. 4). Most of the species held in collection are known to inhabit terrestrial environments or freshwaters and their surroundings; only a small part thrives preferentially in brackish or marine waters. Some genera, i.e. Stichococcus or Porphyridium, thrive in moist terrestrial areas, intermittently submerged banks of rivers as well as saltmarshes and soils of sea-cliffs, including brackish and marine situations, thus showing a cosmopolitan growth attitude. Information about general environments of ACUF strains are showed in the Venn's diagram (Fig. 5a).

The geographic localization of our terrestrial and freshwater strains is quite diverse; 132 strains over the total were collected in Italy, whereas the remaining 534 were sampled or acquired from all over the world (Fig. 5b). This is especially true for Cyanidiophyceae which have been 


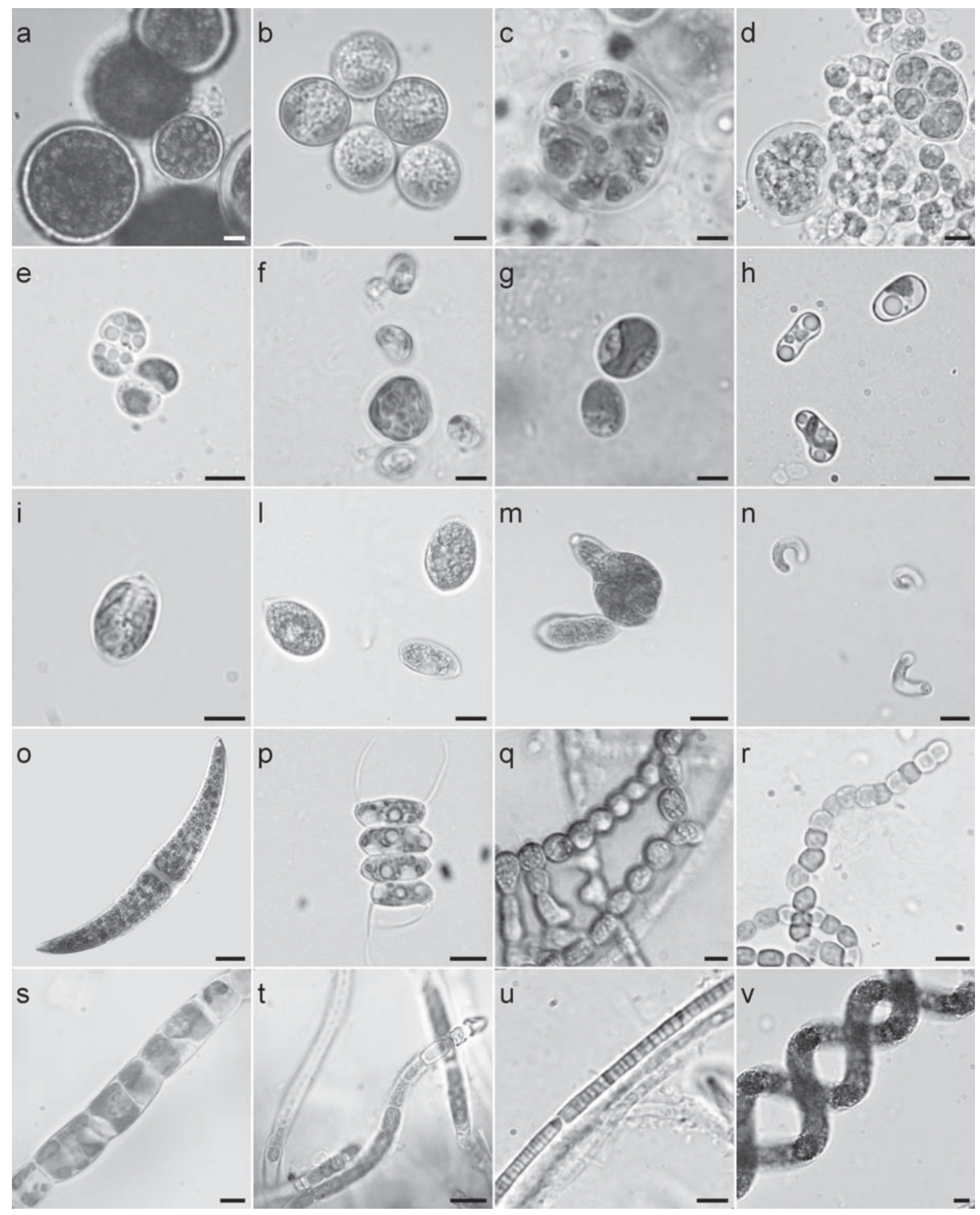

Fig. 4. Examples of microorganisms maintained in the ACUF collection. a) Haematococcus lacustris (Girod-Chantrans) Rostaf.; b) Graesiella emersonii (Shihara et Krauss) Nozaki, Katagiri, Nakagawa, Aizawa et Watanabe; c) Chlorosarcinopsis sp.; d) Scenedesmus sp.; e) Pseudococcomyxa simplex (Mainx) Fott; f) Isochrysis galbana Parke; g) Viridiella fridericiana Albertano, Pollio et Taddei; h) Stichococcus bacillaris Nägeli; i) Tetraselmis suecica (Kylin) Butcher; 1) Oocystis marssonii Lemm.; m) Chlorolobion braunii (Nägeli) Komárek; n) Raphidocelis subcapitata (Korshikov) Nygaard, Komárek, Kristiansen et Skulberg; o) Closterium ehrenbergii Meneghini ex Ralfs; p) Scenedesmus quadricauda (Turpin) Bréb; q) Westiellopsis sp.; r) Anabaena sp.; s) Klebsormidium flaccidum (Kützing) Silva, Mattox et Blackwell; t) Calothrix membranacea Shmidle; u) Leptolyngbya boryana (Gomont) Anagnostidis et Komárek; v) Arthrospira platensis Gomont. Scale bar $5 \mu \mathrm{m}$ 
sampled in hot volcanic and/or acidic sites mainly from Iceland, Turkey, and Italy but also strains from USA, former URSS, Mexico, and Japan (Ciniglia et al., 2004; Yoon et al., 2006).

The research projects in which the ACUF staff is involved since 1973 and the sampling campaigns in archaeological sites and volcanic environments in recent years allowed the ACUF collection to own 556 original cultures, 249 of which are strains acquired from other collections and institutes (Fig. 5c).

\section{Perspectives}

ACUF collection is continuously enriching its heritage with sampling campaigns in extreme environments and archaeological sites to preserve biodiversity and understand ecological and physiological features of photosynthetic inhabitants of extreme environments. For this aim, also the improvement of strain conservation and countermeasures to contamination are required to keep the collection alive and functioning. Recently, a flow cytometry protocol has been developed at ACUF to discriminate and sort the $C$. caldarium and $G$. sulphuraria, which have very poor and overlapping morphology, without the aid of fluorescent probes.

Microalgae from extreme environments adapt to survive in harsh conditions, facing severe oscillations in nutrient availability and other relevant microclimatic parameters. Hot springs, acidic ponds, stone surfaces, high peaks and salty lakes may host microorganism that enact a marvellous strategy for their living, hiding a precious genetic diversity and, in some cases, even more precious skills.

Since last decade, microalgae have been considered a new frontier in the energy biorefinery field because the "fuel only" (Zhu, 2015) option is difficult to achieve. To reduce the considerable cost of production and harvesting, that represents a true bottleneck in the pipeline, the "biorefinery" concept is extending to all compounds in these microorganisms that may be valuable. Microalgae are rich in proteins, polyunsaturated fat acids (PUFA), carbohydrates, and pigments with anti-oxydizing activity. ACUF host laboratory is currently involved to expand algal screenings among extremophilic microalgae to find thermostable antioxydants (Carfagna et al., 2018), based on previous studies showing the potential use of Galdiera sulphuraria in food industry (Graziani et al., 2013).

However, because of the multiple potential in biotechnological applications, the demand for G. sulphuraria from the ACUF collection has increased in recent years.

The ACUF holds one of the largest and most diverse collection of Cyanidiales isolated from thermo-acidic environments of different continents. Moreover, it houses many cyanobacterial and algal isolates from monuments and artworks, that could serve as a platform for in vitro studies on biodeterioration.

Among the stakeholders and collaborators, there are: Roy J. Carver Center for Comparative Genomics, University of Iowa - USA, that studied the biodiversity of this genus in partnership with ACUF; Department of Biology, University of York - United Kingdom; University College London - United Kingdom; Botanisches Institut, University of Köln - Germany; Laboratory of Cell Cycles of Algae Institute of Microbiology Algatech - Czech Republic; Fermentalg - France. Besides, an on-going collaboration is presently held between ACUF and ATI-biotech - Italy for research and production of compounds in the field of food sustainability.

Future perspectives are oriented to the investigation and the screening of microalgae from extreme environments for the production of thermostable and valuable compounds that may find wider application in the field of food sustainability, chemicals for industrial employment, and useful coupled bioprocesses for the optimization of phytoremediation strategies and industrial biomass production and harvesting. For this aim, a continuous work in the preservation and study of biodiversity is still required to understand the ecological conditions in which such special strains are found to dwell.
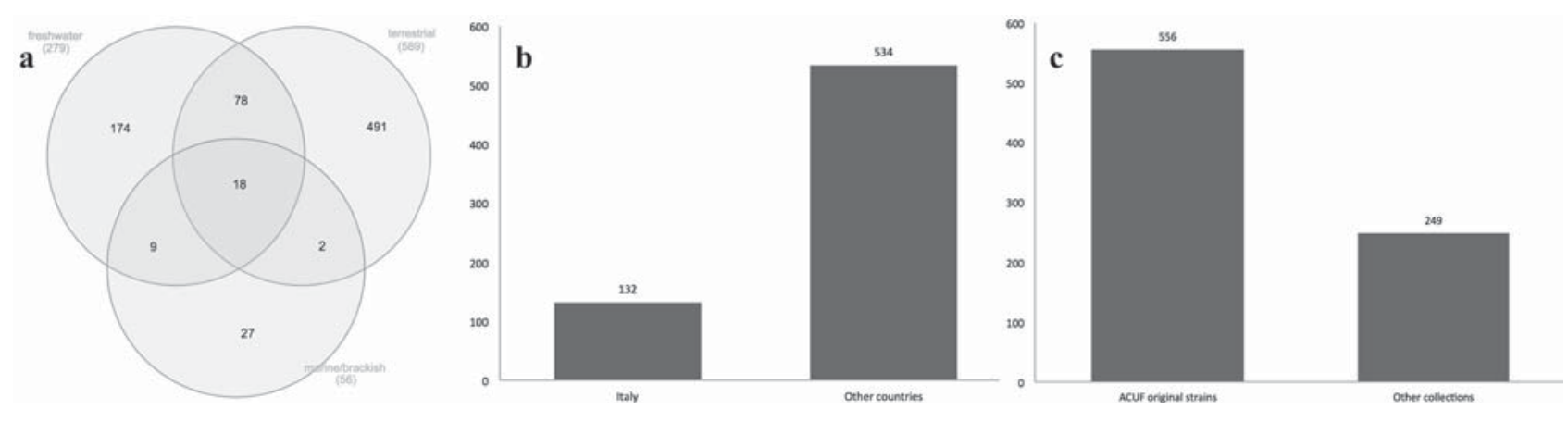

Fig. 5. a) habitats of ACUF algal strains, b, c) supplementary information on ACUF strains 


\section{Acknowledgements}

The authors gratefully thank Olga Mascolo, Giuseppe Palma, Mariagioia Petraretti and Luca Russo for their valuable technical support.

\section{References}

Albertano P., Pinto G., Pollio A., 1994, Ecophysiology and ultrastructure of an acidophilic species of Ochromonas (Chrysophyceae, Ochromonadales), Archiv Für Protistenkunde 144: 75-82.

Albertano P., Pinto G., Pollio A., Taddei R., 1991, Physiological, biochemical, and ultrastructural characters of some strains of Viridiella fridericiana (Chlorophyta, Chlorococcales), Archiv Für Protistenkunde 139: 11723.

Albertano P., Pinto G., Pollio A., Taddei R., 1990, Morphology, ultrastructure and ecology of an acidophilic alga, Pseudococcomyxa simplex (Mainx) Fott (Chlorococcales), Algological Studies/Archiv Für Hydrobiologie S59: 81-95.

Albertano P., Taddei R., 1984, Chlorella protothecoides Krüger var. acidicola, a new variety from very low $\mathrm{pH}$ environments, Algological Studies/Archiv Für Hydrobiologie 37: 401-408.

Allen M. B., 1959, Studies with Cyanidium caldarium, an anomalously pigmented chlorophyte, Archiv fur Mikrobiologie 32: 270-277.

Aminot A., Rey F., 2000, Standard procedure for the determination of chlorophyll a by spectroscopic methods international council for the exploration of the sea, Conseil International Pour l'Exploration de La Mer, Copenhagen, Denmark.

Bischoff H. W., Bold H. C., 1963, Some soil algae from enchanted rock and related algal species, Phycological Studies IV, Austin Texas Publication 6318: 1-95.

Bold H. C., 1949, The morphology of Chlamydomonas chlamydogama, sp. nov. Bulletin of the Torrey Botanical Club 76(2): 101-108.

Borderie F., Denis M., Barani A., Alaoui-Sossé B., Aleya L., 2016, Microbial composition and ecological features of phototrophic biofilms proliferating in the Moidons Caves (France): investigation at the single-cell level, Environmental Science and Pollution Research 23(12): 12039-12049.

Caisová L., Marin B., Melkonian M., 2013, A consensus secondary structure of ITS2 in the chlorophyta identified by phylogenetic reconstruction, Protist 164 (4): 482-96.

Carfagna S., Landi V., Coraggio F., Salbitani G., Vona V., Pinto G., Pollio A., Ciniglia C., 2018, Different char- acteristics of C-phycocyanin (C-PC) in two strains of the extremophilic Galdieria phlegrea, Algal Research 31: 406-12.

Ciniglia C., Yang E. C., Pollio A., Pinto G., Iovinella M., Vitale L., Yoon H. S., 2014, Cyanidiophyceae in Iceland: plastid $r b c \mathrm{~L}$ gene elucidates origin and dispersal of extremophilic Galdieria sulphuraria and G. maxima (Galdieriaceae, Rhodophyta). Phycologia 53(6): 54251.

Ciniglia C., Cennamo P., De Stefano M., Pinto G., Caputo P., Pollio A., 2007, Pinnularia obscura Krasske (Bacillariophyceae, Bacillariophyta) from acidic environments: characterization and comparison with other acid-tolerant Pinnularia species, Fundamental and Applied Limnology / Archiv Für Hydrobiologie 170(1): 29-47.

Ciniglia C., Cascone C., Lo Giudice R., Pinto G., Pollio A., 2005, Application of methods for assessing the genoand cytotoxicity of Triclosan to C. ehrenbergi, Journal of Hazardous Materials 122(3): 227-32.

Ciniglia C., Yoon H. S., Pollio A., Pinto G., Bhattacharya D., 2004, Hidden biodiversity of the extremophilic Cyanidiales red algae, Molecular Ecology 13(7): 1827-38.

Cozzolino S., Pinto G., Pollio A., De Luca P., 1999, Lack of trnL intron in the thermoacidophilic red alga Galdieria sulphuraria (Galdieri) Merola, Plant Biosystems 133(3): 303-5.

De Luca P., Musacchio A., Taddei R., 1981, Acidophilic algae from the fumeroles of Mount Lawu (Java), locus classicus of Cyanidium caldarium Geitler, Giornale Botanico Italiano 115: 1 -9.

De Luca P., Moretti A., Taddei R., 1976-77, Presenza di Cyanidioschyzon merolae De Luca, Taddei, Varano in ambienti acidi extraeuropei (U.S.A. e Indonesia), Delpinoa n.s. 18-19: 69 -76.

De Luca P., Taddei R., Varano L., 1978, Cyanidioschyzon merolae: a new alga of thermal acidic environments, Webbia 33(1): 37-44.

De Luca P., Moretti A., Taddei R., 1972-73, Nuove stazioni di Cyanidium caldarium nell'Italia meridionale ed in Sicilia, Delpinoa n.s. 14-15: 49-60.

Del Mondo A., Pinto G., De Natale A., Pollio A., 2017, In vitro colonization experiments for the assestmentas mycelial growth on a tuff substratum by a Fusarium solani strain isolated from the Oplontis (Naples, Italy) archeological site, International Journal of Conservations Science 8(4): 651-62.

Doyle J. J., Doyle J. L., 1990, Isolation of plant DNA from fresh tissue, Focus 12: 13-15.

Dubelaar G. B. J., Jonker R. R., Jonker R. R., 2000, Flow cytometry as a tool for the study of phytoplankton, Scientia Marina 64(2): 135-56.

Fama P., Wysor B., Kooistra W. H. C. F., Zuccarello G. C., 2002, Molecular phylogeny of the genus Caulerpa 
(Caulerpales, Chlorophyta) inferred from chloplast tufA gene, Journal of Phycology 38(5): 1040-50.

Ferrari B., Paxéus N., Lo Giudice R., Pollio A., Garric J., 2003, Ecotoxicological impact of pharmaceuticals found in treated wastewaters: study of carbamazepine, clofibric acid, and diclofenac. Ecotoxicology and Environmental Safety 55(3): 359-70.

Fuíková K., Flechtner V. R., Lewis L. A., 2013, Revision of the genus Bracteacoccus Tereg (Chlorophyceae, Chlorophyta) based on a phylogenetic approach, Nova Hedwigia 96(1-2): 15-59.

Gambardella R., Moretti A., Musacchio A., 1979-80, Autoecologia ed ultrastruttura di alghe termoacidofile del nord e centro America, Delpinoa n.s. 21-22: 35-45.

Gifuni I., Olivieri G., Pollio A., Franco T. T., Marzocchella A., 2017, Autotrophic starch production by Chlamydomonas species. Journal of Applied Phycology 29(1): 105-14.

Gifuni I., Olivieri G., Pollio A., Marzocchella A., 2018, Identification of an industrial microalgal strain for starch production in biorefinery context: the effect of nitrogen and carbon concentration on starch accumulation. New Biotechnology 41: 46-54.

Graziani G., Schiavo S., Nicolai M. A., Buono S., Fogliano V., Pinto G., Pollio A., 2013, Microalgae as human food: chemical and nutritional characteristics of the thermo-acidophilic microalga Galdieria sulphuraria, Food Function 4(1): 144-52.

Hall J. D., Fuwíková K., Lo C., Lewis A L., Karol K. G., 2010, An assessment of proposed DNA barcodes in freshwater green algae, Cryptogamie, Algologie 31(4): 529-55.

Hirose H., 1958, Rearrangement of the systematic position of a thermal alga, Cyanidium caldarium, Botanical Magazine, Tokyo 71: 347 -352.

Holzinger A., Karsten U. 2013, Desiccation stress and tolerance in green algae: consequences for ultrastructure, physiological and molecular mechanisms, Frontiers in Plant Science 4: 327.

Hyka P., Lickova S., Přibyl P., Melzoch K., Kovar K., 2013, Flow Cytometry for the Development of Biotechnological Processes with Microalgae, Biotechnology Advances 31: 2-16.

Izabela R., Katarzyna G., Borys K., Agnieszka M., Ignacy G.W., Maciej G., 2008, 3D chloroplast structure. In: Allen J.F., Gantt E., Golbeck J.H., Osmond B. (eds) Photosynthesis. Energy from the Sun. Springer, Dordrecht.

Janda J. M., Abbott S. L., 2007, 16S rRNA Gene Sequencing for bacterial identification in the diagnostic laboratory: pluses, perils, and pitfalls, Journal of Clinical Microbiology 45: 2761-64.

Manen J. F., Jacques F., 2002, The cpcB -cpcA Locus as a tool for the genetic characterization of the genus Arthrospira (Cyanobacteria): evidence for horizontal transfer, International Journal of Systematic and Evolutionary Microbiology 52: 861-67.

Marasco A., Nocerino S., Pinto G., Pollio A., Trojsi G., De Natale A., 2016, Weathering of a Roman mosaic-A biological and quantitative study on in vitro colonization of calcareous tesserae by phototrophic microorganisms, Plos One 11.

Meneghini G., 1839, Nuova specie di alga descritta dal sig. Dott. Giuseppe Meneghini di Padova, Nuovo Giornale De' Letterati 39: 67-68.

Merola A., Castaldo R., De Luca P., Gambardella R., Musacchio A., Taddei R., 1981, Revision of Cyanidium caldarium. Three species of acidophilic algae, Giornale Botanico Italiano 115: 189-95.

Müller K. M., Oliveira M. C., Sheath R. G., Bhattacharya D., 2001, Ribosomal DNA phylogeny of the Bangiophycidae (Rhodophyta) and the origin of secondary plastids, American Journal of Botany 88: 1390-400.

Olivieri G., Marzocchella A., Salatino P., Andreozzi R., Pinto G., Pollio A., 2010, Bio -oil production by Stichococcus strains in laboratory scale photobioreactors, Journal of Biotechnology 150: 18.

Organization for Economic Co -operation and development, 1993, OECD guidelines for testing of chemicals 201 -alga, growth inhibition test. OECD guidelines for the testing of chemicals, vol. 1, Paris.

Pinto G., Pollio A., Previtera L., Stanzione M., Temussi F., 2003, Removal of low molecular weight phenols from olive oil mill wastewater using microalgae, Biotechnology Letters 25: 1657-59.

Pinto G., Taddei R., 1976-77, Le alghe delle acque e dei suoli acidi italiani, Delpinoa n.s. 18-19: 77-106.

Pollio A., Aliotta G., Pinto G., Paterno M., Bevilacqua A., 1997, Ecophysiological characters and biochemical composition of Stichococcus bacillaris Naegeli strains from low $\mathrm{pH}$ environments, Algological Studies/Archiv Für Hydrobiologie S84: 129-43.

Pollio A., Cennamo P., Ciniglia C., De Stefano M., Pinto G., Huss V. A., 2005, Chlamydomonas pitschmannii Ettl, a little known species from thermoacidic environments, Protist 156: 287-302.

Rampelotto P., 2013, Extremophiles and extreme environments, Life 3: 482-85.

Rippka R., Deruelles J., Waterbury J., Herdman M., Stanier R., 1979, Generic assignments, strain histories and properties of pure cultures of cyanobacteria, Journal of General Microbiology, 111: 1-61.

Rippka R., Waterbury J. B., Stanier R. Y,. 1981, Isolation and purification of cyanobacteria: some general principles, In: Starr M. P., Stolp H., Trüper H. G., Balows A., Schlegel H. G. (eds) The Prokaryotes. Springer, Berlin, Heidelberg, 212-20.

Ruiz G.J., Olivieri G., de Vree J., Bosma R., Willems P., Reith H., Eppink M., Kleinegris D., Wijffels R., Barbo- 
sa M.J., 2016, Towards industrial products from microalgae, Energy and Environmental Science, 9(10):30363043.

Trask B. J., van den Engh G. J., Elgershuizen J. H., 1982, analysis of phytoplankton by flow cytometry, Cytometry 2(4): 258-64.

U.S. EPA, 1989, Algal (Selenastrum capricornutum) growth test. Short - term methods for estimating the chronic toxicity of effluents and receiving waters to freshwater organisms, Environmental Monitoring Systems Laboratory, Environmental Protection Agency, Cincinnati, Ohio.

Vieira H.H., Bagatini I. L., Guinart C. M., Vieira H. A. A., 2016, tufA Gene as molecular marker for freshwater Chlorophyceae, Algale 31: 155-65.

Walker J. J., Pace N. R., 2007, Endolithic microbial ecosystems, Annual Review of Microbiology 61: 331-47.

Wang X. C., Chang L., Liang H., Bengtsson-Palme J., Chen H., Zhang J. H., Cai D., Li J. Q., 2015, ITS1 a DNA barcode better than ITS2 in eukaryotes? Molecular Ecology Resources 15(3): 573 -86.

Wellburn A. R., 1994, The spectral determination of chlorophylls a and $\mathrm{b}$, as well as total carotenoids, using various solvents with spectrophotometers of different resolution, Journal of Plant Physiology 144: 307-13.
WWAP (United Nations World Water Assessment Programme), 2015, The United Nations World Water Development Report 2015: Water for a sustainable world. Paris, UNESCO.

Yoon H. S., Hackett J. D., Pinto G., Bhattacharya D., 2002 Nonlinear partial differential equations and applications: from the cover: the single, ancient origin of chromist plastids, Proceedings of the National Academy of Sciences 99: 15507-12.

Yoon H. S., Ciniglia C., Wu M., Comeron J. M., Pinto G., Pollio A., Bhattacharya D., 2006, Establishment of endolithic populations of extremophilic Cyanidiales (Rhodophyta), BMC Evolutionary Biology 6: 78.

Zehr J. P., Mellon M. T., Hiorns W. D., 1997, Phylogeny of cyanobacterial nifH genes: evolutionary implications and potential applications to natural assemblages, Microbiology 143: 1443-50.

Zhu L., 2015, Biorefinery as a promising approach to promote microalgae industry: an innovative framework, Renewable and Sustainable Energy Reviews 41: 137684.

Zou S., Fei C., Wang C., Gao Z., Bao Y., He M., Wang C., 2016, How DNA barcoding can be more effective in microalgae identification: a case of cryptic diversity revelation in Scenedesmus (Chlorophyceae), Scientific Reports 6: 36822 . 